\title{
Preparation of high-efficiency ceramic planar membrane and its application for water desalination
}

\author{
Shan $\mathrm{TAO}^{a}$, Yan-Dong XU ${ }^{a}$, Jian-Qiang $\mathrm{GU}^{b}$, Hamidreza ABADIKHAH ${ }^{b}$, \\ Jun-Wei WANG ${ }^{b, *}$ Xin $\mathrm{XU}^{b}$ \\ ${ }^{a}$ Sinopec Northwest Oilfield Branch, Research Institute of Petroleum Engineering, Ürümqi 830001, China \\ ${ }^{b}$ CAS Key Laboratory of Materials for Energy Conversion, Department of Materials Science and Engineering, \\ University of Science and Technology of China, Hefei 230026, China
}

Received: November 07, 2017; Revised: January 26, 2018; Accepted: January 29, 2018

(C) The Author(s) 2018. This article is published with open access at Springerlink.com

\begin{abstract}
Highly efficient $\mathrm{Si}_{3} \mathrm{~N}_{4}$ ceramic planar membrane for water desalination process using membrane distillation was prepared by the dual-layer phase inversion tape casting and sintering method. In comparison with typical phase inversion tape casting method, the green tape was formed using $\mathrm{Si}_{3} \mathrm{~N}_{4}$ slurry on the top and graphite slurry on the bottom. After consuming away the graphite structure, a ceramic membrane consisting of a two-layered structure (skin and finger-like layers) was obtained. The skin layer was relatively tight, and thus could act as a functional layer for separation, while the finger-like layer contained straight open pores with a diameter of $100 \mu \mathrm{m}$, acting as a support with low transport resistance. For comparison, typical $\mathrm{Si}_{3} \mathrm{~N}_{4}$ ceramic membrane was fabricated by phase inversion technique without graphite substrate, resulting in a three-layered structure (skin, finger-like, and sponge layers). After membrane modification from hydrophilic to hydrophobic with polymer derived nanoparticle method, the water desalination performance of the membranes was tested using the sweeping gas membrane distillation (SGMD) with different $\mathrm{NaCl}$ feed solutions. With the increase of salt content from 4 to $12 \mathrm{wt} \%$, the water flux decreased slightly while rejection rate maintained over $99.99 \%$. Comparing with typical three-layered $\mathrm{Si}_{3} \mathrm{~N}_{4}$ membrane, an excellent water flux enhancement of over $83 \%$ was resulted and the rejection rate remained over $99.99 \%$.
\end{abstract}

Keywords: dual-layer phase inversion tape casting; graphite; full-inorganic hydrophobic membrane; membrane distillation

\section{Introduction}

Clean water demand has been one of the most serious global problems during last decade [1,2]. Membrane distillation (MD) is regarded as an increasing water supply method due to zero discharge and high water

* Corresponding author.

E-mail: wjw@ustc.edu.cn recovery ( $\sim 80 \%$ for seawater) [3]. The concentrated discharges from MD can be used in industry as raw material (e.g., food industry).

$\mathrm{MD}$ is a thermally driven separation process, where mass transfer is realized by evaporation of a volatile solvent through the membrane, while non-volatile substances such as ions, macromolecules, colloids, and cell are rejected by the membrane structure [4-6]. Currently, the most common hydrophobic membranes 
in MD are made of polymers including polypropylene (PP), polytetrafluoroethylene (PTFE), and polyvinylidenefluoride (PVDF) [6-9]. Compared to polymeric membranes, ceramic membranes can withstand harsh environments due to their excellent mechanical strength, chemical stability, and thermal resistance [10-12]. Many researches have been reported to explore ceramic membrane application in MD [13-16]. Recently, inorganic modifiers were used for ceramic membrane modification to achieve hydrophobic structure. These kinds of membranes retained the hydrophobicity under harsh conditions and exhibited satisfactory long-term stability, which are proposing the application of ceramic membrane in membrane distillation [17]. In our last few works, phase inversion tape casting method has been investigated for preparation of porous ceramic membrane to enhance the mass transfer. The typical three-layered hydrophobic $\mathrm{Si}_{3} \mathrm{~N}_{4}$ ceramic membrane consists of skin layer, vertical finger-like voids, and sponge-like region $[17,18]$. Sponge layer in conventional three-layered membrane structure is considered as an obstacle against gas transmission which is restricting their application in MD process.

In this work, to overcome this demerit, the sponge layer was removed by a dual-layer tape casting method with a graphite sacrifice layer and carbonation reaction at the bottom of the green tape. The $\mathrm{Si}_{3} \mathrm{~N}_{4}$ membrane showed satisfying water desalination performance, wherein emerging its potential for practical applications.

\section{Experiment}

\subsection{Fabrication of ceramic membranes}

Commercially available $\alpha-\mathrm{Si}_{3} \mathrm{~N}_{4}$ (SN-ESP, Ube Industries, Ltd.; $\alpha$-phase $>95 \%$, average particle size: $0.55 \mu \mathrm{m}$ ), graphite powders (Furunda Co., Ltd., Shandong, China; average particle size: $1.05 \mu \mathrm{m}$ ), $\mathrm{Al}_{2} \mathrm{O}_{3}$ and $\mathrm{Y}_{2} \mathrm{O}_{3}$ (both from Sinopharm Chemical Reagent Co., Ltd., Shanghai, China) were used as starting powders. The dispersant O-(2-aminopropyl)-O'-(2-methoxyethyl)-polypropyleneglycol (AMPG) $\left(M_{\mathrm{w}}=600\right.$, Sigma-Aldrich Co., Ltd., USA) and the binder polyethersulfone (PESf) (Radel A-100, Solvay Advanced Polymers) were dissolved in N-methyl-2-pyrrolidone (NMP) (CP, Sinopharm Chemical Reagent Co., Ltd., Shanghai, China). Then the starting powder mixtures were added into the polymer solution, followed by planetary milling to form a stable suspension. $\mathrm{Si}_{3} \mathrm{~N}_{4}$ slurry and graphite slurry were milled separately for $24 \mathrm{~h}$, with the compositions which have been presented in Table 1. The as-prepared slurries were degassed for 30 min using a vacuum pump. Then the two slurries were co-tape cast on a Mylar sheet with a doctor blade, as shown in Fig. 1. The blade heights for the graphite and ceramic slurry were 0.15 and $0.85 \mathrm{~mm}$, respectively. The membrane was coded as M2.

In order to compare the structure of conventional three-layered ceramic membrane with the present two-layered structure (M2), $\mathrm{Si}_{3} \mathrm{~N}_{4}$ ceramic membrane was prepared through phase inversion process. The $\mathrm{Si}_{3} \mathrm{~N}_{4}$ slurry was cast on a Mylar sheet of gap height $1.0 \mathrm{~mm}$. The membrane was coded as M1.

The cast slurries were solidified by immersion in water for $10 \mathrm{~h}$ at room temperature and then dried at ambient conditions. After that, the green tape was cut into round or rectangular pieces followed by sintering in a graphite furnace at $1700{ }^{\circ} \mathrm{C}$ under flowing $\mathrm{N}_{2}$ atmosphere $(500 \mathrm{~mL} / \mathrm{min})$ for $4 \mathrm{~h}$.

\section{2 Surface modification}

Both the membranes were ultrasonic treated in ethanol for $0.5 \mathrm{~h}$. M2 was slightly polished to remove any impurities from the surface of the membrane. Then the membranes were immersed in boiling $\mathrm{NaOH}$ aqueous solution $(0.2 \mathrm{M})$ for $10 \mathrm{~min}$ to modify the membrane surface for the grafting reaction. Dichloromethylsilane

Table 1 Compositions of precursor slurries

\begin{tabular}{ccc}
\hline Composition & Ceramic slurry (wt \%) & Graphite slurry (wt\%) \\
\hline$\alpha-\mathrm{Si}_{3} \mathrm{~N}_{4}$ & 49.02 & - \\
$\mathrm{Al}_{2} \mathrm{O}_{3}$ & 1.05 & - \\
$\mathrm{Y}_{2} \mathrm{O}_{3}$ & 2.64 & - \\
$\mathrm{NMP}$ & 37.65 & 67.11 \\
$\mathrm{PESf}$ & 7.53 & 6.71 \\
Graphite & - & 25.17 \\
$\mathrm{PVP}$ & - & 1.01 \\
$\mathrm{AMPG}$ & 2.11 & - \\
\hline
\end{tabular}

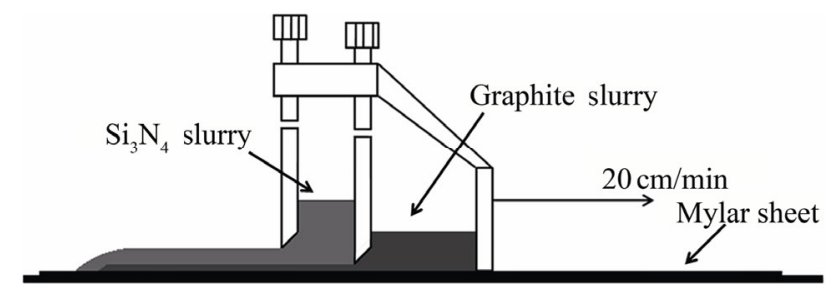

Fig. 1 Schematic illustration of the doctor blade system for phase inversion tape casting. 
and dichlorodimethylsilane (Adamas Reagent Co., Ltd.) as the raw materials were first dissolved in $\mathrm{n}$-heptane (Sinopharm Chemical Reagent Co., Ltd.). Then the prepared membranes were immersed into the mixture solution and held in a boron nitride boat. The boat was heated in a box-type resistance furnace under ammonia atmosphere, with the temperature increase to $150{ }^{\circ} \mathrm{C}$ at heating rate of $3{ }^{\circ} \mathrm{C} / \mathrm{min}$, and held for $30 \mathrm{~min}$ to evaporate solvent. Then, the temperature was raised to $600{ }^{\circ} \mathrm{C}$ at heating rate of $4{ }^{\circ} \mathrm{C} / \mathrm{min}$. Before cooling it down, the temperature was retained for $60 \mathrm{~min}$. The modified ceramic membranes were immersed into ethanol solvent and then ultraphonic treated for $10 \mathrm{~min}$ for further cleaning.

\section{3 Characterization}

The crystalline phases were detected by X-ray diffraction analysis (XRD, Philips PW 1700) using the $\mathrm{Cu} \mathrm{K} \alpha 1$ radiation at a scanning rate of $2\left(^{\circ}\right) / \mathrm{min}$. The morphology of the membrane surface was studied using a scanning electron microscope (SEM, JEOLJSM-6390LA, Japan). The bending strength was tested by a three-point bending method (INSTRON Model 5567, UK) with a maximum load cell of $1 \mathrm{kN}$. Water contact angle was measured using an apparatus (SL200B, Solon Tech Co., Ltd., Shanghai, China). The porosity of the membrane was determined by the Archimedes method. The pore size distribution of the membranes was determined by the bubble point method $[19,20]$.

Gas permeation properties were measured using nitrogen. The sample was fixed on the base of a male connector, and then covered by a refined cylinder. Nitrogen was fed into the cylinder at different pressures, and the gas permeation through the fiber sample was measured by a soap bubble flow meter.

\section{4 Water desalination}

Membrane distillation process was carried out with a home-made device shown in our previous work [17]. Nine membranes with a total area of $25 \mathrm{~cm}^{2}$ were fixed in a steel plate which was separating a steel-made chamber into two compartments (the width of each compartment, i.e., the span between the membrane and the outer wall, was $2 \mathrm{~mm}$ ). A feed solution was pumped into one compartment at a flow rate of $100 \mathrm{~L} / \mathrm{h}$. The water vapor of the feed solution passed through the membranes to the other compartment. Then, the water vapor was taken by nitrogen on the permeate side and condensed in the chiller. Sweeping gas flow was $500 \mathrm{~mL} / \mathrm{min}$. The condensed water was collected in a glass bottle and weighed using an electronic balance. The conductivities of the feed solution and the permeate were measured by a conductivity meter (FE30, Mettler Toledo). The $\mathrm{NaCl}$ rejection $R$ was calculated by

$$
R=\left(1-\frac{C_{\mathrm{p}}}{C_{\mathrm{f}}}\right) \times 100 \%
$$

where $C_{\mathrm{f}}$ and $C_{\mathrm{p}}$ are the conductivities of the feed solution and permeate water, respectively $[21,22]$.

\section{Results and discussion}

\section{1 Membrane characteristics}

According to Figs. 2(a) and 2(b), with a sacrifice layer, we successfully remove sponge region by dual-layer phase inversion tape casting method, while the skin layer and finger-like layer have remained constantly. Figure 2(c) shows the microstructure of the skin layer. Porous rod-like $\mathrm{Si}_{3} \mathrm{~N}_{4}$ grains were disordered assembled in three-dimensional space. As shown in Fig. 2(d), finger-like pores penetrate through the membrane cross section and expose at the bottom surface. The skin layer has remained as the functional layer which decreases the water vapor transfer resistance and increases permeate flux in SGMD. The bending strength of M2 is $25 \mathrm{MPa}$, which is comparable with ceramic membranes reported in the literature [23,24].

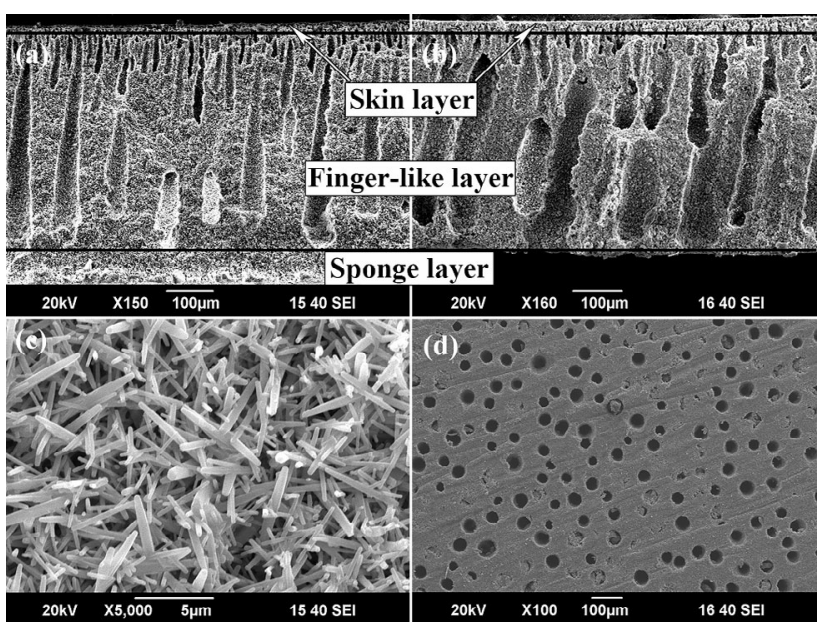

Fig. 2 Microstructure of the membrane: (a) cross section of M1; (b) cross section of M2; (c) top surface structure of M2; (d) bottom surface structure of M2. 
The X-ray diffractograms of the M2 membranes sintered at $1700{ }^{\circ} \mathrm{C}$ are shown in Fig. 3. The initial membrane containing black graphite layer in the bottom side, shows $\mathrm{Si}_{3} \mathrm{~N}_{4}, \mathrm{SiC}$, and $\mathrm{C}$ phases. Although after ultrasound treatment, the black layer is removed and green $\mathrm{SiC}$ is emerging at the surface of the membrane, the impurity phase is still observed in the XRD spectra. After slight polishing, pure $\mathrm{Si}_{3} \mathrm{~N}_{4}$ phase has been resulted. In the sintering procedure, carbonation reaction occurs in the mixing layer of sponge-like region, which helps to form a separate layer. This layer has been completely removed by slight polishing as reveled in the XRD result.

Surface modification was carried out with an organosilane-derived inorganic particle product. It is an efficient and long-term stable modifier to embellish the membrane hydrophobicity, according to our previous work [17]. As we can see in Fig. 4, water contact angle is about $142^{\circ}$ for M1 and $140^{\circ}$ for M2. Both the membranes show hydrophobicity.

In Fig. 5, the pore size distributions of M1 and M2 membranes are depicted. It can be seen that both the membranes exhibit a homogeneous pore size distribution. The pore size distribution of M2 is calculated in the range of $0.80-1.05 \mu \mathrm{m}$ and the average pore size is about $0.91 \mu \mathrm{m}$, while $0.82 \mu \mathrm{m}$ has resulted for M1 membrane. According to the principle of the bubble-point method, the pore size corresponds to the narrowest position of through pores, i.e., the pore throat. So this pore diameter is associated with the pores of the skin layer for M2 and skin layer-sponge layer for M1. The porosity is increased from $48 \%$ (M1) to $57 \%$ (M2), according to the Archimedes method.

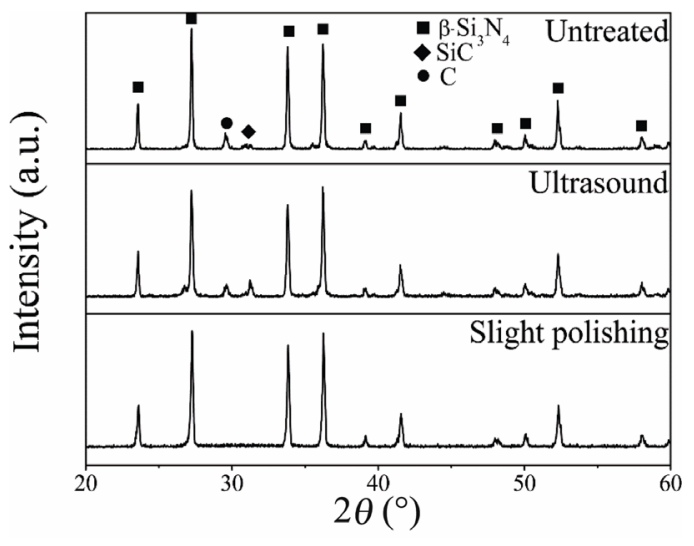

Fig. 3 XRD spectra of the sintered membranes.

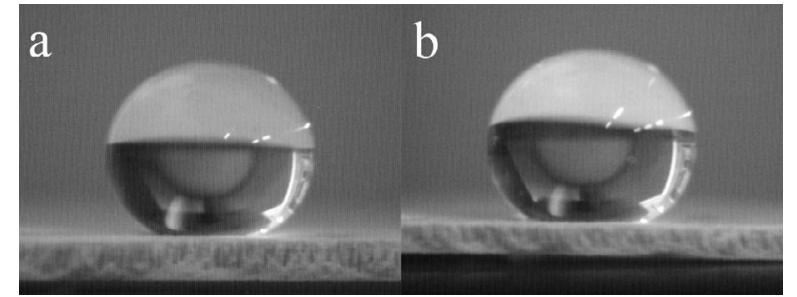

Fig. 4 Water contact angles after the modification: (a) M1; (b) M2.

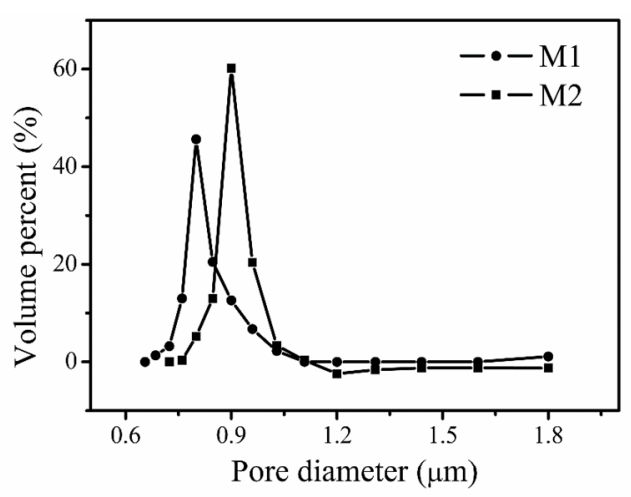

Fig. 5 Pore size distributions of the membranes.

As shown in Fig. 6, gas permeation has been dramatically increased by removing sponge layer of membrane. The gas permeation of both membranes decreases slightly after modification, which can be explained by the reduction of pore size distribution or clogging the membrane pores with deposition of the modifier particles on the pore walls of the membrane. More than $100 \%$ enhancement of gas permeation is attained from $3.28 \times 10^{6} \mathrm{~L} /\left(\mathrm{m}^{2} \cdot\right.$ day $)$ to $6.90 \times 10^{6} \mathrm{~L} /\left(\mathrm{m}^{2} \cdot\right.$ day $)$ at $0.01 \mathrm{MPa}$ for $\mathrm{M} 1$ and $\mathrm{M} 2$, respectively. M1 comprises a low-porosity skin layer at the top, a finger-

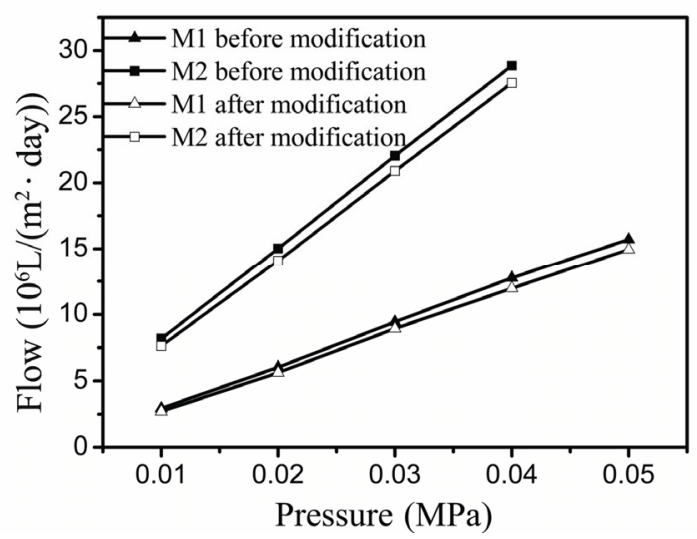

Fig. 6 Gas permeation of the membranes before and after modification. 
like porous layer in the middle, and a sponge-like layer at the bottom. The gas transmission process consists of several steps in series. First, the gas is transferred through the small pores of the top layer following by transition through the finger-like large pores in the middle layer. In the next, the gas phase is passed through the small pores in the bottom layer. The sponge-like layer acts as an extra diffusion barrier for the gas transmission. Therefore, higher efficient separation process is attained with a two-layered structure (M2).

\section{2 Membrane distillation}

Membrane distillation was carried out with a homemade device (Section 2.4). The feed solutions contained $4-12 \mathrm{wt} \% \mathrm{NaCl}$. Sweeping gas flow was fixed at $500 \mathrm{~mL} / \mathrm{min}$. The temperature on the permeate side was room temperature $\left(2{ }^{\circ} \mathrm{C}\right)$. Figure 7 shows the permeate flux of M1 and M2 as a function of the feed temperature with $4 \mathrm{wt} \% \mathrm{NaCl}$ content. The permeate flux enhances quickly when the feed temperature increases from 45 to $75{ }^{\circ} \mathrm{C}$ for both membranes.

The MD flux is proportional to the transmembrane water vapor pressure difference: $\Delta P=P_{\mathrm{f}}-P_{\mathrm{p}}$. The water vapor pressure at the water side of the membrane, $P_{\mathrm{f}}$, is written as follows [25]:

$$
\begin{aligned}
P_{\mathrm{f}}= & \exp \left(\frac{C_{1}}{T_{\mathrm{f}}}+C_{2}+C_{3} T_{\mathrm{f}}+C_{4} T_{\mathrm{f}}^{2}+C_{5} T_{\mathrm{f}}^{3}+C_{6} \ln T_{\mathrm{f}}\right) . \\
& \left(1-\chi_{\mathrm{f}}\right)\left(1-0.5 \chi_{\mathrm{f}}-10 \chi_{\mathrm{f}}^{2}\right)
\end{aligned}
$$

where $C_{1}-C_{6}$ are constants: $C_{1}=-5.8002206 \times 10^{3}$, $C_{2}=-5.516256, \quad C_{3}=-4.8640239 \times 10^{-2}, \quad C_{4}=$ $4.1764768 \times 10^{-5}, \quad C_{5}=-1.4452093 \times 10^{-8}, \quad C_{6}=$ 6.5459673. $P_{\mathrm{f}}$ is expressed in $\mathrm{kPa}$ and $T_{\mathrm{f}}$ in $\mathrm{K}$. In the $4 \mathrm{wt} \% \mathrm{NaCl}$ solution, the mole fraction is 0.0127 . Table 2 shows the $P_{\mathrm{f}}$ values at different temperatures.

The pressure at the permeate side, $P_{\mathrm{p}}$, is calculated as follows [25]:

$$
P_{\mathrm{p}}=\frac{\omega P}{\omega+0.622}
$$

Although the humidity ratio along the membrane module, $\omega$, is unknown, but this parameter is correlated with the $\mathrm{N}_{2}$ flux, $m_{\mathrm{a}}$, and the value of the humidity at the module inlet, $\omega_{\text {in }}$, through following equation:

$$
\omega=\omega_{\text {in }}+\frac{N A}{m_{\mathrm{a}}}
$$

The humidity of the inlet $\mathrm{N}_{2}$ was 0 . Membrane area was $25 \mathrm{~cm}^{2}$. Sweeping gas flow was $500 \mathrm{~mL} / \mathrm{min}$.
According to the flux of the process, the pressure of the permeate side and the driving force could be calculated for both membranes, as shown in Table 2.

Therefore, higher temperature enhances the permeate flux. It reaches $6.40 \mathrm{~L} /\left(\mathrm{m}^{2} \cdot \mathrm{h}\right)$ for $\mathrm{M} 1$ and $11.75 \mathrm{~L} /\left(\mathrm{m}^{2} \cdot \mathrm{h}\right)$ for $\mathrm{M} 2$ at $75{ }^{\circ} \mathrm{C}$, while the rejection rate remains over 99.99\%. Comparing M1 and M2, a great water flux enhancement of over $83 \%$ occurs at $75{ }^{\circ} \mathrm{C}$ after removing the sponge layer.

Figure 8 shows the water flux of M1 and M2 in different $\mathrm{NaCl}$ solutions. $4-12 \mathrm{wt} \% \mathrm{NaCl}$ concentrations were used as feed solutions, and the sweeping gas pressure was fixed at 0.15 bar and the temperature was fixed at $75{ }^{\circ} \mathrm{C}$. With salt concentration increasing, the water flux decreases slightly from $6.40 \mathrm{~L} /\left(\mathrm{m}^{2} \cdot \mathrm{h}\right)$ at 4 wt $\%$ to $5.00 \mathrm{~L} /\left(\mathrm{m}^{2} \cdot \mathrm{h}\right)$ at $12 \mathrm{wt} \%$ for $\mathrm{M} 1$ and from $11.75 \mathrm{~L} /\left(\mathrm{m}^{2} \cdot \mathrm{h}\right)$ at $4 \mathrm{wt} \%$ to $9.19 \mathrm{~L} /\left(\mathrm{m}^{2} \cdot \mathrm{h}\right)$ at $12 \mathrm{wt} \%$ for M2. According to the equations of transmembrane water vapor pressure difference, Eq. (2) and Eq. (3), the driving force decreases with increasing salt concentration. Thus, the flux is decreasing with increasing of salt concentration. All the rejection rates are over $99.99 \%$. It has retained a good flux and high rejection rate at high salt content. Over $83 \%$ enhancement of water flux is gained at different concentration $\mathrm{NaCl}$ feed solutions.

Table 2 Transmembrane water vapor pressure difference of the membranes

\begin{tabular}{cccccccc}
\hline \multirow{2}{*}{ Temperature $\left({ }^{\circ} \mathrm{C}\right)$} & \multicolumn{3}{c}{$\mathrm{M} 1(\mathrm{~Pa})$} & & \multicolumn{3}{c}{$\mathrm{M} 2(\mathrm{~Pa})$} \\
\cline { 2 - 4 } \cline { 6 - 8 } & $P_{\mathrm{f}}$ & $P_{\mathrm{p}}$ & $\Delta P$ & $P_{\mathrm{f}}$ & $P_{\mathrm{p}}$ & $\Delta P$ \\
\hline 45 & 9395.6 & 16.3 & 9379.3 & 9395.6 & 28.6 & 9367.0 \\
55 & 15435.1 & 36.8 & 15398.3 & 15435.1 & 55.8 & 15379.3 \\
65 & 24552.9 & 59.1 & 24463.8 & 24552.9 & 93.2 & 24429.7 \\
75 & 37797.4 & 86.9 & 37710.5 & 37797.4 & 159.3 & 37639.1 \\
\hline
\end{tabular}

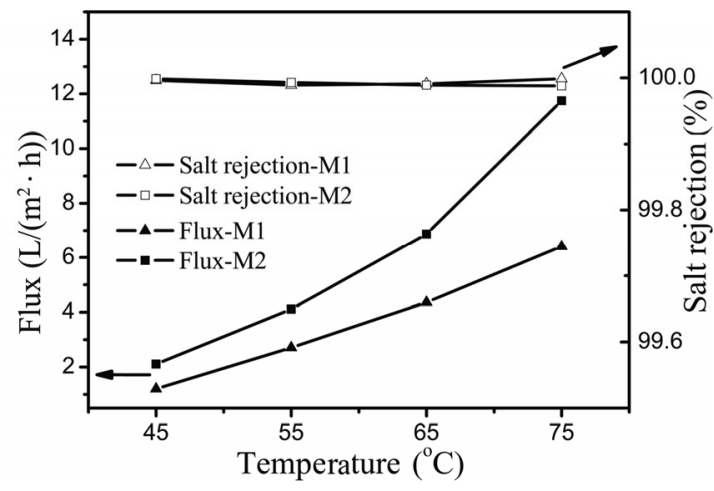

Fig. 7 Water flux of M1 and M2 as a function of the feed temperature. 


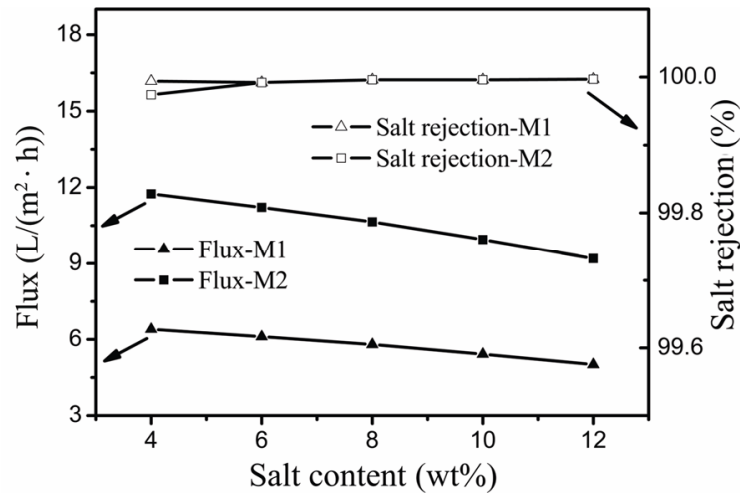

Fig. 8 Water flux of M1 and M2 as a function of the feed $\mathrm{NaCl}$ solution.

The mean free path of the water molecules at 0 $100{ }^{\circ} \mathrm{C}$ is $0.2 \mu \mathrm{m}$. Its value is comparable with the membrane pore size. The vapor transmission takes place via a combined Knudsen-molecular diffusion flow. The following relationship is applied for calculation of mass transport coefficient $B$ :

$$
B=\frac{N}{\Delta P}
$$

So the mean mass transport coefficient is $0.1805 \mathrm{~L} /\left(\mathrm{m}^{2} \cdot \mathrm{h} \cdot \mathrm{kPa}\right)$ for $\mathrm{M} 1$ and $0.3394 \mathrm{~L} /\left(\mathrm{m}^{2} \cdot \mathrm{h} \cdot \mathrm{kPa}\right)$ for M2.

\section{Conclusions}

High-efficiency two-layered ceramic planar membrane was prepared by the double-layer phase inversion tape casting and sintering method. The skin layer was relatively tight which acts as a functional layer, while the finger-like layer contained straight open pores, acting as a support with low transport resistance. In comparison with the membranes prepared by typical phase inversion tape casting method, the average pore size has increased slightly from 0.82 to $0.91 \mu \mathrm{m}$, while more than $100 \%$ enhancement of gas permeation was attained from $3.28 \times 10^{6}$ to $6.90 \times 10^{6} \mathrm{~L} /\left(\mathrm{m}^{2} \cdot\right.$ day $)$ at $0.01 \mathrm{MPa}$. The surface of the membrane was modified from hydrophilic to hydrophobic via grafting with inorganic SiNCO nanoparticles. The membrane showed a good performance of high salt concentration. With salt content increasing, water flux decreased slightly from $11.75 \mathrm{~L} /\left(\mathrm{m}^{2} \cdot \mathrm{h}\right)$ at $4 \mathrm{wt} \%$ to $9.19 \mathrm{~L} /\left(\mathrm{m}^{2} \cdot \mathrm{h}\right)$ at $12 \mathrm{wt} \%$, while the rejection rate remained over $99.99 \%$. Comparing with typical phase inversion three-layered structure $\mathrm{Si}_{3} \mathrm{~N}_{4}$ membrane, a great enhancement over
$83 \%$ of the water flux was achieved.

\section{Acknowledgements}

This research was supported by the National Natural Science Foundation of China (Grant Nos. 51372238, U1732115, and 11435012), the CNPC-CAS Strategic Cooperation Research Program (Grant No. 2015A-4812), and demonstration project of key technologies for EOR of carbonate oil and gas fields in Tarim Basin (national major project of China, Grant No. 2016ZX05053).

\section{References}

[1] Kim SJ, Ko SH, Kang $\mathrm{KH}$, et al. Direct seawater desalination by ion concentration polarization. Nat Nanotechnol 2010, 5: 297-301.

[2] Li X, Yu X, Cheng C, et al. Electrospun superhydrophobic organic/inorganic composite nanofibrous membranes for membrane distillation. ACS Appl Mater Interfaces 2015, 7: 21919-21930.

[3] Subramani A, Jacangelo JG. Emerging desalination technologies for water treatment: A critical review. Water Res 2015, 75: 164-187.

[4] Lawson KW, Lloyd DR. Membrane distillation. J Membrane Sci 1997, 124: 1-25.

[5] Khayet M. Membranes and theoretical modeling of membrane distillation: A review. Adv Colloid Interfac 2011, 164: $56-88$.

[6] Eykens L, De Sitter K, Dotremont C, et al. Membrane synthesis for membrane distillation: A review. Sep Purif Technol 2017, 182: 36-51.

[7] Liao Y, Loh C-H, Wang R, et al. Electrospun superhydrophobic membranes with unique structures for membrane distillation. ACS Appl Mater Interfaces 2014, 6 : 16035-16048.

[8] Lin S, Nejati S, Boo C, et al. Omniphobic membrane for robust membrane distillation. Environ Sci Technol Lett 2014, 1: 443-447.

[9] Zhou T, Yao Y, Xiang R, et al. Formation and characterization of polytetrafluoroethylene nanofiber membranes for vacuum membrane distillation. J Membrane Sci 2014, 453: 402-408.

[10] Krivoshapkina EF, Krivoshapkin PV, Vedyagin AA. Synthesis of $\mathrm{Al}_{2} \mathrm{O}_{3}-\mathrm{SiO}_{2}-\mathrm{MgO}$ ceramics with hierarchical porous structure. $J A d v$ Ceram 2017, 6: 11-19.

[11] Liu X, Demir NK, Wu Z, et al. Highly water-stable zirconium metal-organic Framework UiO-66 membranes supported on alumina hollow fibers for desalination. $\mathrm{J} \mathrm{Am}$ Chem Soc 2015, 137: 6999-7002.

[12] Zhang J-W, Fang H, Wang JW, et al. Preparation and characterization of silicon nitride hollow fiber membranes for seawater desalination. J Membrane Sci 2014, 450: 


\section{7-206.}

[13] Kujawa J, Kujawski W, Koter S, et al. Membrane distillation properties of $\mathrm{TiO}_{2}$ ceramic membranes modified by perfluoroalkylsilanes. Desalin Water Treat 2013, 51: 1352-1361.

[14] Kujawa J, Cerneaux S, Koter S, et al. Highly efficient hydrophobic titania ceramic membranes for water desalination. ACS Appl Mater Interfaces 2014, 6: 14223-14230.

[15] Kujawa J, Cerneaux S, Kujawski W, et al. Hydrophobic ceramic membranes for water desalination. Appl Sci 2017, 7: 402-413.

[16] García-Fernández L, Wang B, García-Payo $\mathrm{MC}$, et al. Morphological design of alumina hollow fiber membranes for desalination by air gap membrane distillation. Desalination 2017, 420: 226-240.

[17] Wang J-W, Li L, Gu J-Q, et al. Highly stable hydrophobic SiNCO nanoparticle-modified silicon nitride membrane for zero-discharge water desalination. AIChE $J$ 2017, 63: 1272-1277.

[18] Ren C, Fang H, Gu J, et al. Preparation and characterization of hydrophobic alumina planar membranes for water desalination. J Eur Ceram Soc 2015, 35: 723-730.

[19] Jakobs E, Koros WJ. Ceramic membrane characterization via the bubble point technique. J Membrane Sci 1997, 124: 149-159.

[20] Kujawski W, Adamczak P, Narebska A. A fully automated system for the determination of pore size distribution in microfiltration and ultrafiltration membranes. Separ Sci
Technol 1989, 24: 495-506.

[21] Wang J-W, Li L, Zhang J-W, et al. $\beta$-SiAlON ceramic hollow fiber membranes with high strength and low thermal conductivity for membrane distillation. $J$ Eur Ceram Soc 2016, 36: 59-65.

[22] Zhang J, Dow N, Duke M, et al. Identification of material and physical features of membrane distillation membranes for high performance desalination. J Membrane Sci 2010, 349: 295-303

[23] Kritikaki A, Tsetsekou A, Fabrication of porous alumina ceramics from powder mixtures with sol-gel derived nanometer alumina: Effect of mixing method. $J$ Eur Ceram Soc 2009, 29: 1603-1611.

[24] Qi H, Fan Y, Xing W, et al. Effect of $\mathrm{TiO}_{2}$ doping on the characteristics of macroporous $\mathrm{Al}_{2} \mathrm{O}_{3} / \mathrm{TiO}_{2}$ membrane supports. J Eur Ceram Soc 2010, 30: 1317-1325.

[25] Khayet M, Godino P, Mengual JI. Nature of flow on sweeping gas membrane distillation. J Membrane Sci 2000 , 170: $243-255$.

Open Access The articles published in this journal are distributed under the terms of the Creative Commons Attribution 4.0 International License (http://creativecommons.org/licenses/by/4.0/), which permits unrestricted use, distribution, and reproduction in any medium, provided you give appropriate credit to the original author(s) and the source, provide a link to the Creative Commons license, and indicate if changes were made. 